\title{
Genetic and environmental influence on thyroid gland volume and thickness of thyroid isthmus: a twin study
}

Adam Domonkos Tarnoki ${ }^{*}$, David Laszlo Tarnoki ${ }^{*}$, Gabor Speer ${ }^{2 *}$, Levente Littvay ${ }^{3}$, Pal Bata' ${ }^{1}$, Zsolt Garami ${ }^{4}$, Viktor Berczi', Kinga Karlinger ${ }^{1}$

\begin{abstract}
Objectives: Decreased thyroid volume has been related to increased prevalence of thyroid cancer Subjects and methods: One hundred and fourteen Hungarian adult twin pairs (69 monozygotic, 45 dizygotic) with or without known thyroid disorders underwent thyroid ultrasound. Thickness of the thyroid isthmus was measured at the thickest portion of the gland in the midline using electronic calipers at the time of scanning. Volume of the thyroid lobe was computed according to the following formula: thyroid height ${ }^{*}$ width* depth ${ }^{*}$ correction factor (0.63). Results: Age-, sex-, body mass indexand smoking-adjusted heritability of the thickness of thyroid isthmus was $50 \%$ (95\% confidence interval [Cl], 35 to $66 \%)$. Neither left nor right thyroid volume showed additive genetic effects, but shared environments were $68 \%(95 \% \mathrm{Cl}, 48$ to $80 \%)$ and $79 \%(95 \% \mathrm{Cl}, 72$ to $87 \%)$, respectively. Magnitudes of monozygotic and dizygotic co-twin correlations were not substantially impacted by the correction of covariates of body mass index and smoking. Unshared environmental effects showed a moderate influence on dependent parameters (24-50\%). Conclusions: Our analysis support that familial factors are important for thyroid measures in a general twin population. A larger sample size is needed to show whether this is because of common environmental (e.g. intrauterine effects, regional nutrition habits, iodine supply) or genetic effects. Arch Endocrinol Metab. 2015;59(6):487-94
\end{abstract}

Keywords

Heritability; goiter; thyroid gland; isthmus; thyroid cancer

\author{
1 Department of Radiology and \\ Oncotherapy, Semmelweis \\ University, Budapest, Hungary \\ ${ }^{2}$ Department of Medicine, Policlinic \\ of Hospitaller Brothers of St. John \\ of Good, Budapest, Hungary \\ ${ }^{3}$ Central European University, \\ Budapest, Hungary \\ ${ }^{4}$ Houston Methodist DeBakey Heart \\ \& Vascular Center, The Houston \\ Methodist Hospital, Houston, TX, USA \\ ${ }^{*}$ These authors contributed \\ equally to the study
}

Correspondence to: Adam Domonkos Tarnoki Department of Radiology and Oncotherapy, Semmelweis University 78/A Üllöi street, 1082 Budapest, Hungary tarnoki2@gmail.com

Received on July/20/2015 Accepted on Aug/19/2015

DOI: 10.1590/2359-3997000000110

\section{INTRODUCTION}

$\mathrm{T}$ hyroid disorders such as nontoxic and toxic goiter are relevant diseases in previously and currently iodine-deficient areas from the public-health and the clinical point of view (1). Iodine supply is inadequate in most parts of Hungary, however, inadequate iodine intake has remained a nation-wide health problem. Based on WHO's European Iodine Deficiency report Hungary belongs to mild iodine deficient (50-99 $\mu \mathrm{g} / \mathrm{l})$ countries, like many part of Europe (2).

In thyroid-healthy populations the thyroid volume can influence a risk assessment for malignant thyroid disease (3) and the serum calcitonin concentration (4). In case of any thyroid disease, the thyroid volume is also a risk and a prognostical factor of the disease procession $(5,6)$. Thyroid volume can be easily measured by ultrasound, and it is influenced by several factors, such as thyroid autoimmunity, serum Thyroid Stimu- lating Hormone (TSH), free (f) T4 and fT3 levels (7), serum selenium concentration $(2,8)$, body mass index (BMI) and body surface area (BSA) (9), smoking (10), alcohol consumption (11), and impaired glucose metabolism (12). An association between thyroid volume and serum calcitonin has been established $(2,8)$. Studies have investigated the thyroid function on atrial fibrillation and blood pressure as well $(13,14)$.

Additional data support the significant role of genetic factors in the etiology of thyroid volume (simple goiter). Males generally had higher thyroid volumes than females (15). Thyroid asymmetry has been associated with the handedness and the position of the esophagus (16). The effect of age on thyroid volume depends on iodine status. The prevalence of thyroid cancer is higher in patients with low thyroid volume (3). Accordingly, there is an increasing interest towards the importance of thyroid volume. 
Our aim was to assess how much the thyroid volume is influenced by modifiable environmental factors, and how large is the genetic predisposition.

\section{SUBJECTS AND METHODS}

\section{Participants and study design}

This cross-sectional twin study included 228 healthy adult twins (69 monozygotic, 45 same-sex dizygotic twin pairs) recruited from the Hungarian Twin Registry (17). We considered only the same-sex dizygotic twin pairs to avoid bias of the heritability estimates in the presence of gender specific or X chromosome effects. Exclusion criteria included pregnancy, and any foreseeable lack of compliance with test procedures. Subjects with acute or chronic thyroid disease were included in the analysis. Instead of genotyping for zygosity classification, we used a multiple-choice self-reported seven-part questionnaire which has an accuracy of over 99\% (18). Age, height, weight, history of thyroid disease, smoking habits, known thyroid disease, surgeries and medications were recorded for each patient. All participants gave informed consent. The study was approved by the Ethical Committee of Semmelweis University and was conducted in full compliance with regulations of the Declaration of Helsinki.

\section{Thyroid ultrasound assessment}

Thyroid ultrasound testing was conducted at the Department of Radiology and Oncotherapy, Semmelweis University in 2009 and 2010 by using B-mode ultrasonography (Esaote MyLab 70X Vision, Esaote, Genova, Italy) equipped with a linear array transducer (13 MHz, LA523). The gray-scale amplification gain, the time-gain compensation curve, and focus number were adjusted to acquire the best images of the thyroid glands. The examinations were performed by the same experienced sonographer in patients in supine position. Coronal plane images were obtained either from the long-axis view, and transversal plane images were applied for axial views (Figure 1). All thyroid glands were completely visible and measurable. Thickness of the thyroid isthmus was measured at the thickest portion of the gland in the midline using electronic calipers at the time of scanning (Figure 1). Standardized static original digital images were recorded and these images were retrospectively examined by a specialized radiologist blinded to the participants' twinship and clinical characteristics in order to confirm the accuracy of the measurements. Volume of the thyroid lobe was computed according to the following formula: thyroid height $\mathrm{x}$ width $\mathrm{x}$ depth $\mathrm{x}$ correction factor (0.63) (19).
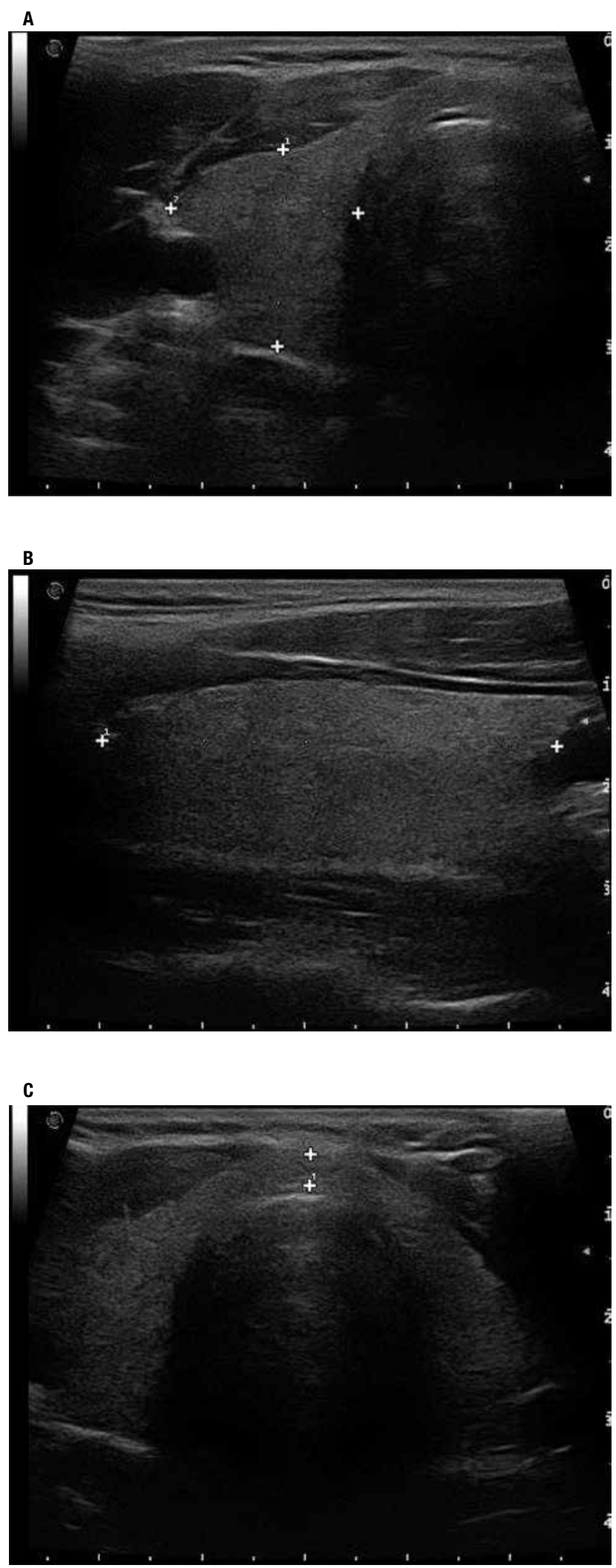
D

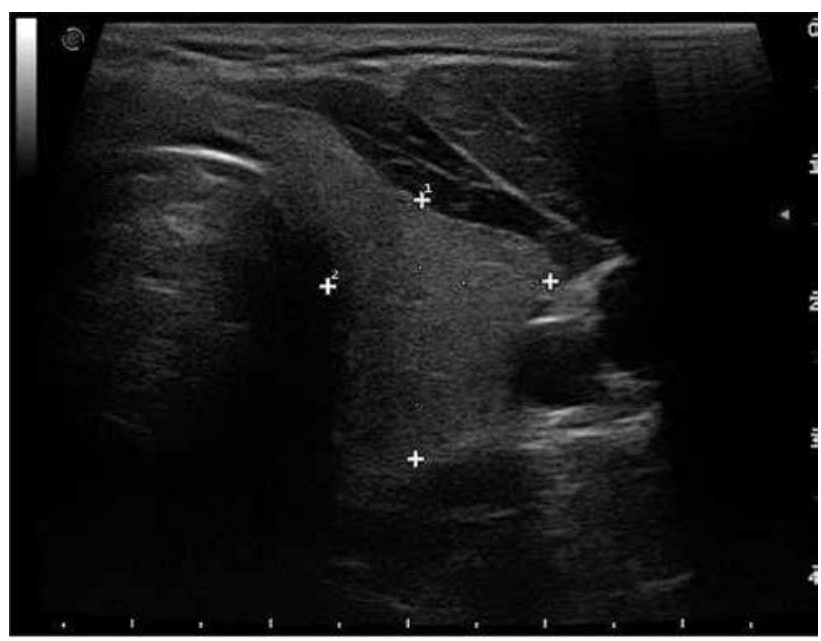

E

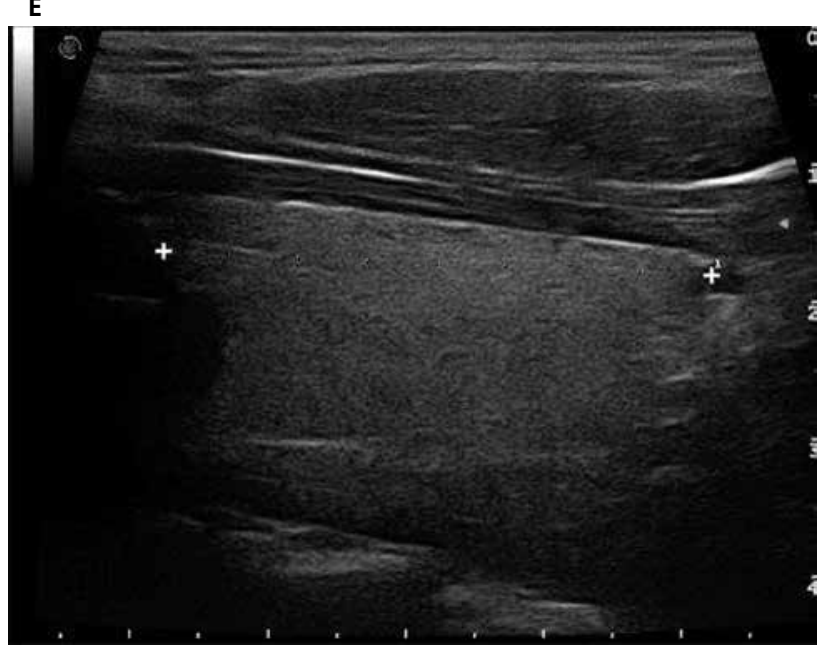

Figure 1. Measurement of the thyroid volume and isthmus using electronic calipers at the time of scanning. Transversal plane images were applied for axial views $(A, D)$ and coronal plane images were obtained either from the long-axis view bilaterally $(B, E)$. Thickness of the thyroid isthmus was measured at the thickest portion of the gland in the midline (C).

\section{Statistical analysis}

SPSS Statistics 17 (SPSS Inc., Chicago, IL, USA) was used to perform the descriptive analysis (mean, standard deviation, and percentage for categorical variables). Assessing similarities and differences between the $\mathrm{MZ}$ and DZ subsamples was assessed by a parametric difference test. Parametric tests were sufficient as all raw or log-transformed continuous traits were within acceptable parameters of normality and non-parametric tests do not offer such clustering corrections. Thyroid volume parameters failed to show normal distribution for MZ-DZ comparisons and for the correlation analyses were log-normalized.

A descriptive estimate of the genetic influence on a single trait and of the genetic correlation between different traits in monozygotic and dizygotic pairs was calculated using the within-pair co-twin correlations in two models (model- 1 and model-2). The model- 1 corrects for the twins' age and gender. The model-2, in addition to age and gender, also corrects for body mass index and smoking based on the bivariate correlations. Substantially higher MZ co-twin correlation (compared to $\mathrm{DZ}$ correlations) suggests heritability, while similar co-twin correlations imply that shared environmental components drive the variance more strongly. Based on similarities between $\mathrm{MZ}$ and $\mathrm{DZ}$ twins, structural equation modeling (ACE model) was performed by using the Mplus Version 7.l (Muthén \& Muthén, Los Angeles, CA, USA). In the A-C-E model three latent variables, additive genetic effects " $A$ ", common (or shared) environment " $C$ " and unshared (or unique) environment " $E$ " drive the variance in the phenotype for each twin (Figure 2). Two A-C-E models (model-1 and model-2 as used for co-twin correlations) were estimated. In order to find the most parsimonious model for the investigated thyroid traits, besides the fully-fledged ACE models, sub-models were also constructed. The AE model discards the common environmental effects (C), the CE sub-model disregards the additive genetic effects (A), while the E model summarizes all effects, which are completely uncorrelated between twin pairs (not shown in Table 1). Homogeneity of the full ACE and the sub-models were assessed with $\chi^{2}$ tests. We used the Chi-square test as it is the most conservative fit statistic. Acceptable fit to the full model together with lower Akaike and/or Bayesian information criteria helped us to select out the most parsimonious model.

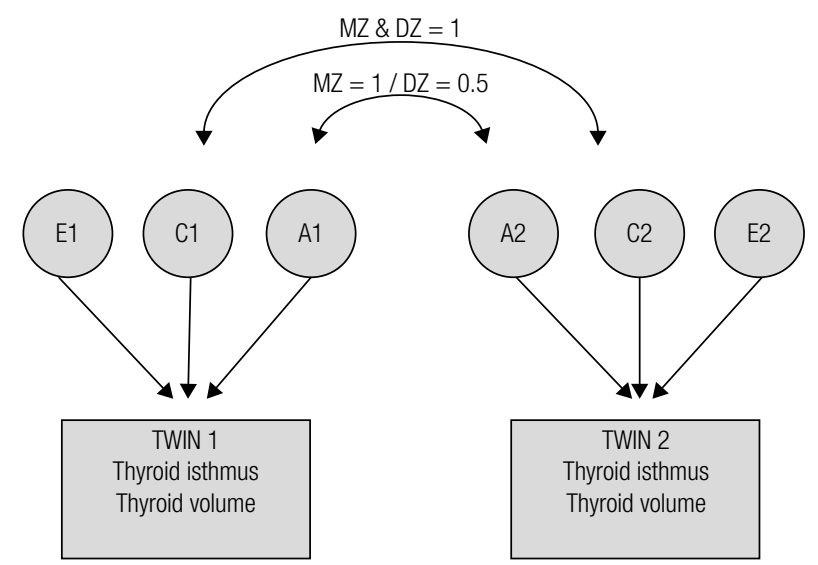

Figure 2. Univariate A-C-E model. Rectangles denote the observed thyroid variables and circles denote the latent variables. Curved arrows denote correlations (fixed at the highlighted values). Straight arrows signify the estimated impact of the latent factor on variance of the observed phenotype. Letters A, C, and E stand for additive genetic, common environmental, and unique environmental influences, respectively. 
Table 1. Parameter estimates for additive hereditary (A), common environment $(C)$ and unique environmental influences (E) on thyroid parameters by structural equation modeling (69 monozygotic, 45 dizygotic twin pairs)

\begin{tabular}{|c|c|c|c|c|c|c|c|c|c|c|c|c|c|c|c|c|}
\hline \multirow{2}{*}{$\begin{array}{c}\text { Dependent } \\
\text { variable }\end{array}$} & & \multirow[b]{2}{*}{ AIC } & \multirow[b]{2}{*}{ BIC } & \multirow[b]{2}{*}{$-2 L L$} & \multicolumn{3}{|c|}{ Overall model fit } & \multicolumn{3}{|c|}{ Comparative model fit } & \multirow[b]{2}{*}{ A } & \multirow[b]{2}{*}{$95 \% \mathrm{Cl}$} & \multirow[b]{2}{*}{ C } & \multirow[b]{2}{*}{$95 \% \mathrm{CI}$} & \multirow[b]{2}{*}{$\mathbf{E}$} & \multirow[b]{2}{*}{$95 \% \mathrm{Cl}$} \\
\hline & & & & & $\begin{array}{c}\text { Chi-sq } \\
\text { Difference }\end{array}$ & $\begin{array}{c}\text { df } \\
\text { Difference }\end{array}$ & p-value & $\begin{array}{c}\text { Chi-sq } \\
\text { Difference }\end{array}$ & $\begin{array}{c}\text { df } \\
\text { Difference }\end{array}$ & p-value & & & & & & \\
\hline \multirow{8}{*}{$\begin{array}{l}\text { Thyroid } \\
\text { isthmus } \\
\text { thickness }\end{array}$} & & & & & & & & & & & \multicolumn{6}{|c|}{ Model-1 estimates } \\
\hline & A-C-E & 589.1 & 605.5 & 577.1 & 8.588 & 12 & 0.7377 & & & & 0.51 & $0.28-0.69$ & 0.00 & $0.00-0.26$ & 0.49 & $0.34-0.65$ \\
\hline & $A-E^{*}$ & 587.1 & 600.8 & 577.1 & 8.588 & 13 & 0.8033 & 0 & 1 & 1 & 0.51 & $0.34-0.65$ & 0.00 & $0.00-0.49$ & 0.49 & $0.35-0.66$ \\
\hline & $C-E$ & 590.6 & 604.3 & 580.6 & 12.105 & 13 & 0.5190 & 3.52 & 1 & 0.006 & 0.00 & $0.00-0.00$ & 0.38 & $0.22-0.52$ & 0.62 & $0.48-0.78$ \\
\hline & & & & & & & & & & & \multicolumn{6}{|c|}{ Model-2 estimates } \\
\hline & A-C-E & 584.8 & 606.6 & 568.8 & 23.323 & 26 & 0.6146 & & & & 0.50 & $0.28-0.68$ & 0.00 & $0.00-0.51$ & 0.50 & $0.33-0.65$ \\
\hline & $A-E^{\star}$ & 582.8 & 601.9 & 568.8 & 23.323 & 27 & 0.6675 & 0 & 1 & 1 & 0.50 & $0.35-0.66$ & 0.00 & $0.00-0.00$ & 0.50 & $0.34-0.65$ \\
\hline & $C-E$ & 586.2 & 605.4 & 572.3 & 26.829 & 27 & 0.4730 & 3.50 & 1 & 0.061 & 0.00 & $0.00-0.00$ & 0.36 & $0.22-0.52$ & 0.64 & $0.48-0.78$ \\
\hline \multirow{8}{*}{$\begin{array}{l}\text { Left lobe } \\
\text { volume }\end{array}$} & & & & & & & & & & & \multicolumn{6}{|c|}{ Model-1 estimates } \\
\hline & $A-C-E$ & 427.5 & 443.9 & 415.5 & 18.571 & 12 & 0.0994 & & & & 0.00 & $0.00-0.00$ & 0.68 & $0.57-0.80$ & 0.32 & $0.20-0.48$ \\
\hline & $A-E$ & 435.1 & 448.8 & 425.1 & 28.216 & 13 & 0.0084 & 9.64 & 1 & 0.002 & 0.69 & $0.53-0.82$ & 0.00 & $0.00-0.00$ & 0.31 & $0.18-0.47$ \\
\hline & $C-E^{\star}$ & 425.5 & 439.2 & 415.5 & 18.571 & 13 & 0.1370 & 0 & 1 & 1 & 0.00 & $0.00-0.00$ & 0.68 & $0.54-0.79$ & 0.32 & $0.21-0.46$ \\
\hline & & & & & & & & & & & \multicolumn{6}{|c|}{ Model-2 estimates } \\
\hline & A-C-E & 426.0 & 447.8 & 410.0 & 35.835 & 26 & 0.0947 & & & & 0.02 & $0.00-0.50$ & 0.64 & $0.46-0.80$ & 0.33 & $0.22-0.53$ \\
\hline & $A-E$ & 431.2 & 450.3 & 417.2 & 43.016 & 27 & 0.0261 & 7.20 & 1 & 0.007 & 0.68 & $0.48-0.80$ & 0.00 & $0.00-0.00$ & 0.32 & $0.20-0.52$ \\
\hline & $C-E^{\star}$ & 424.0 & 443.1 & 410.0 & 35.849 & 27 & 0.1186 & 0 & 1 & 1 & 0.00 & $0.00-0.00$ & 0.66 & $0.51-0.77$ & 0.34 & $0.23-0.49$ \\
\hline \multirow{8}{*}{$\begin{array}{l}\text { Right lobe } \\
\text { volume }\end{array}$} & & & & & & & & & & & \multicolumn{6}{|c|}{ Model-1 estimates } \\
\hline & $A-C-E$ & 408.4 & 424.8 & 396.4 & 10.355 & 12 & 0.5849 & & & & 0.17 & $0.00-0.46$ & 0.63 & $0.36-0.79$ & 0.21 & $0.13-0.29$ \\
\hline & $A-E$ & 414.9 & 428.6 & 404.9 & 18.849 & 13 & 0.1279 & 8.49 & 1 & 0.004 & 0.79 & $0.71-0.87$ & 0.00 & $0.00-0.00$ & 0.21 & $0.13-0.29$ \\
\hline & $C-E^{\star}$ & 407.9 & 421.6 & 397.9 & 11.828 & 13 & 0.5418 & 1.47 & 1 & 0.225 & 0.00 & $0.00-0.00$ & 0.76 & $0.70-0.82$ & 0.24 & $0.18-0.31$ \\
\hline & & & & & & & & & & & \multicolumn{6}{|c|}{ Model-2 estimates } \\
\hline & $A-C-E$ & 407.4 & 429.2 & 391.4 & 30.944 & 26 & 0.2303 & & & & 0.18 & $0.00-0.52$ & 0.61 & $0.28-0.78$ & 0.21 & $0.13-0.29$ \\
\hline & $A-E$ & 413.1 & 432.2 & 399.1 & 38.658 & 27 & 0.0680 & 7.70 & 1 & 0.005 & 0.79 & $0.72-0.87$ & 0.00 & $0.00-0.00$ & 0.21 & $0.13-0.28$ \\
\hline & $C-E^{*}$ & 406.9 & 426.0 & 392.9 & 32.515 & 27 & 0.2135 & 1.50 & 1 & 0.221 & 0.00 & $0.00-0.00$ & 0.76 & $0.68-0.82$ & 0.24 & $0.18-0.32$ \\
\hline
\end{tabular}

Model-1: correlations were adjusted to age and sex.

Model-2: correlations were adjusted to age, sex, body mass index and smoking.

AIC: Akaike information criteria; BIC: Bayesian information criteria; LL: loglikelihood; rMZ - saturated correlation between. monozygotic twins; rDZ - saturated correlation between dizygotic twin. ${ }^{\star}$ Best fitting model.

The results from model-1 tell us the total genetic and environmental impact on the dependent variable. The results from model-2 tell us the impact of genes and the environment after the impact of known risk factors (body mass index, smoking) are corrected for. Empirical 95\% confidence intervals were calculated with a Bollen-Stine Bootstrap. All inferential statistics were estimated using full information maximum likelihood.

\section{RESULTS}

\section{Descriptive analysis of the twin cohort}

There were no significant differences between monozygotic and dizygotic twins in clinical and ultrasonographic characteristics except history of some thyroid disease (Table 2). Two hundred and fifteen subjects (95.1\%) had ultrasonographically homogenous thyroid gland. One hundred and twelve subjects (52.3\%) had no thyroid nodule. Thirty seven (17.3\%) and 65 $(28.5 \%)$ twins had non-cystic and cystic thyroid nodules, respectively.

Heritability analysis of thyroid volume and thickness of thyroid isthmus

Co-twin correlations indicated higher correlation between $\mathrm{MZ}$ twins as $\mathrm{DZ}$ twins in case of thyroid isthmus $(\mathrm{rMZ}=0.520,95 \% \mathrm{CI}, 0.366,0.656, \mathrm{rDZ}=0.192$, $95 \%$ CI, $-0.151,0.444)$. The magnitude of correlation was similar between $\mathrm{MZ}$ and $\mathrm{DZ}$ twins in case of the left and right thyroid volume (left: $\mathrm{rMZ}=0.680$, 
Table 2. Clinical and ultrasonographic characteristics according to zygosity

\begin{tabular}{|c|c|c|c|}
\hline & \multirow{2}{*}{ Total } & \multicolumn{2}{|c|}{ Zygosity } \\
\hline & & Monozygotic & Dizygotic \\
\hline Participants, $n$ & 228 & 138 & 90 \\
\hline Women:men ratio & $164: 64$ & 106:32 & $58: 32$ \\
\hline Age, years (mean \pm standard deviation) & $43.6 \pm 13.6$ & $42.6 \pm 16.4$ & $45.2 \pm 16.3$ \\
\hline Body mass index, $\mathrm{kg} / \mathrm{m}^{2}$ (mean \pm standard deviation) & $25.7 \pm 4.8$ & $25.6 \pm 4.9$ & $25.7 \pm 4.7$ \\
\hline Current smokers, n (\%) & $36(16.1)$ & $21(15.3)$ & $15(17.4)$ \\
\hline Ex smokers, $n(\%)$ & $31(13.9)$ & $17(12.4)$ & $14(16.3)$ \\
\hline Never smokers, n (\%) & $156(70.0)$ & $99(72.3)$ & $57(66.3)$ \\
\hline Thyroid isthmus thickness, $\mathrm{mm}$ (mean \pm standard deviation) & $3.01 \pm 1.09$ & $3.01 \pm 1.10$ & $3.01 \pm 1.08$ \\
\hline Mean left thyroid lobe volume, $\mathrm{mm}^{3}$ (mean \pm standard deviation) & $3366 \pm 2144$ & $3181 \pm 2058$ & $3655 \pm 2255$ \\
\hline Mean right thyroid lobe volume, $\mathrm{mm}^{3}$ (mean \pm standard deviation) & $5096 \pm 3520$ & $4851 \pm 3344$ & $5482 \pm 3765$ \\
\hline \multicolumn{4}{|l|}{ Known thyroid disease, $\mathrm{n}(\%)^{*}$} \\
\hline Hypothyreoidism & $4(1.7)$ & $1(0.7)^{\dagger}$ & $3(3.4)$ \\
\hline Hyperthyreoidism & $4(1.7)$ & $1(0.7)^{\dagger}$ & $3(3.4)$ \\
\hline Goiter & $5(2.2)$ & $5(3.6)^{\dagger}$ & $0(0.0)$ \\
\hline Goiter operation & $3(1.3)$ & $2(1.4)$ & $1(1.1)$ \\
\hline
\end{tabular}

* Defined according to the clinical history and patients referral.

$+P<0.05$ vs dizygotic.

\# No smoking information available in 5 subjects.

95\% CI, 0.480, 0.816, rDZ $=0.692,95 \% \mathrm{CI}, 0.520$, 0.825 ; right: $\mathrm{rMZ}=0.792,95 \% \mathrm{CI}, 0.706,0.872, \mathrm{rDZ}$ $=0.709,95 \%$ CI, 0.582, 0.816). Age-, sex-, body mass index- and smoking-adjusted heritability of the thickness of thyroid isthmus was $50 \%$ (95\% confidence interval $[\mathrm{CI}], 35$ to $66 \%$ ) (Table 1). Neither left nor right thyroid volume showed additive genetic effects, but shared environments were $68 \%$ (95\% CI, 48 to $80 \%$ ) and $79 \%$ (95\% CI, 72 to $87 \%)$, respectively. Comparing model- 1 with model-2, magnitudes of $\mathrm{MZ}$ and $\mathrm{DZ}$ co-twin correlations are not substantially impacted by the correction of relevant covariates.

Using the most parsimonious (the A-E model for thickness of isthmus and the C-E model for both volume parameters) structural equation model (Table 1), unshared environmental effects showed a moderate influence on dependent parameters (24-50\%).

\section{DISCUSSION}

Our analysis support that familial factors are important for thyroid measures. Our results suggest that the greatest part of variance of thyroid volumes is rather explained by shared environmental components. In contrast, thickness of thyroid isthmus seems to be moderately genetically influenced. Genetic studies using the twin design are based upon the assumption that twins are representative of the general population for the outcomes being studied.
Hereditary factors were found to be important in the aetiology of the simple and nodular goitre, Basedow-Graves' disease, Hashimoto's thyroiditis and the regulation of the pituitary-thyroid axis (20-23).

Previous twin studies confirmed the heritability of thyroid hormone levels (plasma TSH: 64\%, fT4: 65\% and fT $3: 64 \%)$ too $(23,24)$ and demonstrated that besides age, BMI, iodine intake, serum TSH concentration, parity and cigarette smoking played a small role in the thyroid size. Genetic loci associated with clinically overt euthyroid multinodular goiter were already mapped in linkage analyses, genome-wide association studies identified four genetic loci associated with thyroid volume and goiter risk (25). In addition, a Danish twin study demonstrated a higher intraclass correlation for thyroid volume in monozygotic twins as compared to dizygotic twins, suggesting that genetic factors account for approximately $61-78 \%$ of the interindividual variation of the thyroid volume (26). In that study, calculation of thyroid volume was based on computerized method, but the entire volume was taken into account and no separate analysis (for left and right lobes, isthmus) was carried out (26). We observed that the magnitude of heritability of thyroid isthmus thickness was similar to that of entire thyroid volume assessed in that Danish study, however, we did not find any significant genetic background neither on the left or right lobe volumes in our study sample. Lack of heritabil- 
ity in our study can be partly caused by the varying magnitude of iodine supply or genetic predisposition between various populations. Since our data set was not very large, it is possible that our result is influenced by sampling random error which makes it difficult to separate genetic effect from common environmental effect. Accordingly, a larger sample size is needed to show whether this is because of common environmental or genetic effects. It is important to take into account that in addition to gender, age, BMI and cigarette smoking, ACE analyses were also adjusted to family history regarding thyroid diseases, pregnancy, use of hormone replacement therapy, supplementary iodine intake, serum TSH, serum free T4, serum free T3, and thyroid antibody status (26). In our study, no pregnant women participated, and thyroid hormone levels were not assessed. However, since thyroid hormone levels are heritable (23), large modifiable effect on our hereditary results (no heritability of thyroid lobe volumes) is not anticipatory. Iodine status did not seem to exert a significant influence on the changes in thyroid volume in a recent study, but changes in BMI levels seemed to be more important (27). In a sample of euthyroid female twins, no evidence of a relationship between skewed X chromosome inactivation pattern and thyroid volume was reported, neither after controlling for zygosity, age, TSH, smoking habits and use of oral contraceptives (28). Although genetic influences were reported to be important in the regulation of total thyroid size in a twin population having no thyroid disorders (26), heritability of thyroid volumes has not been studied in a twin population in both gender without eliminating thyroid disorders.

To date, no study has been performed to evaluate the heritability of the thickness of thyroid isthmus. In former studies, measurement of the thyroid volume was assessed in a different way compared to ours. Thyroid volume was calculated by multiplying the thickness, width, length, by a corrective factor $(0.63)$ for each lobe in our analysis, but others calculated the volumes of thyroid glands according to the ellipsoid formula: volume $(\mathrm{mL})=$ depth $(\mathrm{cm}) \times$ width $(\mathrm{cm}) \times$ length $(\mathrm{cm}) \times \pi / 6$. The total thyroid volume was obtained by combining the volumes of both lobes. The isthmus was never taken into account in volume calculation. The location and morphometric characteristics of the thyroid isthmus shows high interindividual variabilities (29), and this variability is moderately heritable according to our results.
Some previous study reported that smoking has also been associated with increased thyroid volume $(30,31)$. In contrast, a Turkish study found no difference between smokers and non-smokers on mean thyroid gland volume (32). We found a small effect of smoking on thyroid volume in agreement with the study of Hegedüs and cols., but there was no significant effect of smoking and BMI on heritability estimates in models- 2 when these factors were included in the ACE models (30). Thyroid volume is positively correlated with BMI, which is under strong genetic control (33). Since we found no genetic component in thyroid volume regulation, no genetic decomposition model was performed between BMI and thyroid volume due to the possible lack of genetic contribution.

Our study had several limitations. Thyroid hormone levels were not assessed in our study, but we were interested in the magnitude of contribution of environmental factors to the heredity of thyroid volume in a general population without excluding subjects with thyroid disorder. We assumed that the both members of the twins had the same iodine intake, because all of the twin pairs lived in the same area of Hungary. Ultrasonography has a weakness of inter-observer variability but in this study all participants were evaluated by the same sonographer and the results were later checked by a professional radiologist. Additional limitation includes the relatively small number of participating dizygotic twins compared to usual twin studies, which may lead to statistical errors in the ACE analysis by increasing the $\mathrm{E}$ variance. As mentioned above, this fact might influence our results due to the random error effect. In addition, thyroid autoimmunity was not taken into account which may have an influence on thyroid size.

Sonography has become the gold standard for assessment of the thyroid gland in the recent decades (34). Thyroid ultrasound is a widespread technique which is used as a first-line diagnostic procedure for detecting and characterizing thyroid volume and diseases (35). Studies have demonstrated that the evaluation of thyroid volume by ultrasound is an accurate and precise, non-invasive, rapid and inexpensive technique. Our results suggest that thyroid volume is mainly influenced by shared environment, including intrauterine effects (shared womb, epigenetics) and regional nutrition habits (iodine supply). However, larger sample size is needed to confirm the role of genetic effects in the determination of thyroid volume. Modifiable, unshared environment effects (e.g., smok- 
ing, BMI, nutrition habits, alcohol consumption) had a moderate role (24-32\%) in the determination of thyroid lobe volumes. These factors can be eliminated in order to prevent the development of thyroid cancer, whose prevalence is related to low thyroid volume (3). Our data suggest that many different environmental as well as genetic factors are involved - possibly each with small effects - in the size of thyroid gland. Accordingly, the use of thyroid volume for screening may detect thyroid cancer at an earlier stage and overall survival may be improved.

In conclusion, age-, sex-, body mass index- and smoking-adjusted familial factors are important for the determination of the thyroid volume and isthmus thickness. A larger sample size is needed to show whether this is because of common environmental or genetic effects.

Author contributions: Adam Domonkos Tarnoki, David Laszlo Tarnoki, Zsolt Garami, Viktor Berczi, Pal Bata and Kinga Karlinger participated in the design of the study and conceived of the study. Adam Domonkos Tarnoki and David Laszlo Tarnoki carried out the ultrasound studies, participated in the involvement of twins. Gabor Speer and Pal Bata approved and checked the ultrasound study results. Levente Littvay, Adam Domonkos Tarnoki and David Laszlo Tarnoki performed the statistical analysis. All authors drafted the manuscript, read and approved the final manuscript.

Acknowledgment: none.

Funding: none.

Disclosure: no potential conflict of interest relevant to this article was reported.

\section{REFERENCES}

1. Laurberg P, Pedersen KM, Hreidarsson A, Sigfusson N, Iversen E, Knudsen PR. lodine intake and the pattern of thyroid disorders: a comparative epidemiological study of thyroid abnormalities in the elderly in Iceland and in Jutland, Denmark. J Clin Endocrinol Metab. 1998;83(3):765-9.

2. WHO. lodine deficiency in Europe. A continuing public health problem. 2007. Available at: http://www.who.int/nutrition/publications/ VMNIS_lodine_deficiency_in_Europe.pdf. Accessed on: Jan 14, 2014.

3. Duran AO, Anil C, Gursoy A, Nar A, Altundag O, Inanc M, et al. The relationship between thyroid volume and malignant thyroid disease. Med Oncol. 2014;31(1):814.

4. Giovanella L, Imperiali M, Ferrari A, Palumbo A, Lippa L, Peretti A, et al. Thyroid volume influences serum calcitonin levels in a thyroid-healthy population: results of a 3-assay, 519 subjects study. Clin Chem Lab Med. 2012;50(5):895-900.

5. Profilo MA, Sisti E, Marcocci C, Vitti P, Pinchera A, Nardi M, et al. Thyroid volume and severity of Graves' orbitopathy. Thyroid. 2013;23(1):97-102.
6. Karabeyoglu M, Unal B, Dirican A, Kocer B, Gur AS, Bozkurt B, et al. The relation between preoperative ultrasonographic thyroid volume analysis and thyroidectomy complications. Endocr Regul. 2009;43(2):83-7.

7. Andersen S, Pedersen KM, Bruun NH, Laurberg P. Narrow individual variations in serum $\mathrm{T}(4)$ and $\mathrm{T}(3)$ in normal subjects: a clue to the understanding of subclinical thyroid disease. J Clin Endocrinol Metab. 2002;87(3):1068-72.

8. Rasmussen LB, Schomburg L, Köhrle J, Pedersen IB, Hollenbach B, Hög A, et al., Selenium status, thyroid volume, and multiple nodule formation in an area with mild iodine deficiency. Eur $\mathrm{J}$ Endocrinol. 2011;164(4):585-90.

9. lacobellis G, Ribaudo MC, Zappaterreno A, lannucci CV, Leonetti F. Relationship of thyroid function with body mass index, leptin, insulin sensitivity and adiponectin in euthyroid obese women. Clin Endocrinol (Oxf). 2005;62(4):487-91.

10. Vejbjerg $P$, Knudsen N, Perrild H, Carlé A, Laurberg P, Pedersen IB, et al. The impact of smoking on thyroid volume and function in relation to a shift towards iodine sufficiency. Eur J Epidemiol. 2008;23(6):423-9.

11. Valeix $P$, Faure $P$, Bertrais $S$, Vergnaud AC, Dauchet $L$, Hercberg $S$. Effects of light to moderate alcohol consumption on thyroid volume and thyroid function. Clin Endocrinol (Oxf). 2008;68(6):988-95.

12. Anil C, Akkurt A, Ayturk S, Kut A, Gursoy A. Impaired glucose metabolism is a risk factor for increased thyroid volume and nodule prevalence in a mild-to-moderate iodine deficient area. Metabolism. 2013;62(7):970-5.

13. Asvold BO, Bjøro T, Nilsen TI, Vatten LJ. Association between blood pressure and serum thyroid-stimulating hormone concentration within the reference range: a population-based study. $J$ Clin Endocrinol Metab. 2007;92(3):841-5.

14. Gammage MD, Parle JV, Holder RL, Roberts LM, Hobbs FD, Wilson $\mathrm{S}$, et al. Association between serum free thyroxine concentration and atrial fibrillation. Arch Intern Med. 2007;167(9):928-34.

15. Hegedüs L. Thyroid size determined by ultrasound. Influence of physiological factors and non-thyroidal disease. Dan Med Bull. 1990;37(3):249-63.

16. Ying $M$, Yung DM. Asymmetry of thyroid lobe volume in normal Chinese subjects: association with handedness and position of esophagus. Anat Rec (Hoboken). 2009;292(2):169-74.

17. Littvay $L$, Métneki J, Tárnoki $A D$, Tárnoki $D L$. The Hungarian Twin Registry. Twin Res Hum Genet. 2013;16(1):185-9.

18. Heath AC, Nyholt DR, Neuman R, Madden PA, Bucholz KK, Todd $\mathrm{RD}$, et al. Zygosity diagnosis in the absence of genotypic data: an approach using latent class analysis. Twin Res. 2003;6(1):22-6.

19. Harkányi Z, Morvay Z (eds). Ultrasonography. Budapest: Minerva Press; 2006.

20. Brix TH, Kyvik KO, Hegedüs L. Major role of genes in the etiology of simple goiter in females: a population-based twin study. J Clin Endocrinol Metab. 1999;84(9):3071-5.

21. Brix TH, Kyvik KO, Christensen K, Hegedüs L. Evidence for a major role of heredity in Graves' disease: a population-based study of two Danish twin cohorts. J Clin Endocrinol Metab. 2001;86(2):930-4.

22. Brix TH, Kyvik KO, Hegedüs L. A population-based study of chronic autoimmune hypothyroidism in Danish twins. J Clin Endocrinol Metab. 2000;85(2):536-9.

23. Hansen PS, Brix TH, Sørensen TIA, Kyvik KO, Hegedüs L. Major genetic influence on the regulation of the pituitary-thyroid axis: a study of healthy Danish twins. J Clin Endocrinol Metab. 2004;89(3):1181-7.

24. Meikle AW, Stringham JD, Woodward MG, Nelson JC. Hereditary and environmental influences on the variation of thyroid hormones in normal male twins. J Clin Endocrinol Metab. 1988;66(3):588-92. 
25. Teumer A, Rawal R, Homuth G, Ernst F, Heier M, Evert M, et al. Genome-wide association study identifies four genetic loci associated with thyroid volume and goiter risk. Am J Hum Genet. 2011;88(5):664-73.

26. Hansen PS, Brix TH, Bennedbaek FN, Bonnema SJ, Kyvik KO, Hegedüs L. Genetic and environmental causes of individual differences in thyroid size: a study of healthy Danish twins. J Clin Endocrinol Metab. 2004;89(5):2071-7.

27. Eray E, Sari F, Ozdem S, Sari R. Relationship between thyroid volume and iodine, leptin, and adiponectin in obese women before and after weight loss. Med Princ Pract. 2011;20(1):43-6.

28. Brix TH, Hansen PS, Bennedbak FN, Bonnema SJ, Kyvik KO, $\emptyset$ rstavik $\mathrm{KH}$, et al. $\mathrm{X}$ Chromosome inactivation pattern is not associated with interindividual variations in thyroid volume: a study of euthyroid Danish female twins. Twin Res Hum Genet. 2009;12(5):502-6.

29. Won HS, Han SH, Oh CS, Chung IH, Won HJ, Kim JH. Location and morphometry of the thyroid isthmus in adult Korean cadavers. Anat Sci Int. 2013;88(4):212-6.
30. Hegedüs L, Karstrup S, Veiergang D, Jacobsen B, Skovsted L, Feldt-Rasmussen $U$. High frequency of goitre in cigarette smokers. Clin Endocrinol (Oxf). 1985;22(3):287-92.

31. Knudsen N, Bülow I, Laurberg P, Ovesen L, Perrild H, Jørgensen T. Association of tobacco smoking with goiter in a low-iodine-intake area. Arch Intern Med. 2002;162(4):439-43.

32. Aksoy FG, Kesüm Ü. Influence of cigarette smoking on thyroid gland volume: an ultrasonographic approach. Turk J Med Sci. 2002;32:335-8.

33. Tarnoki AD, Tarnoki DL, Medda E, Cotichini R, Stazi MA, Fagnani $\mathrm{C}$, et al. Bioimpedance analysis of body composition in an international twin cohort. Obes Res Clin Pract. 2014;8(3):e201-98.

34. Massol J, Pazart L, Aho S, Strauch G, Leclere J, Durieux P. [Management of the thyroid nodule. Preliminary results of a practice survey of 685 general practitioners and specialists]. Ann Endocrinol (Paris). 1993;54(4):220-5.

35. Hegedüs L. Thyroid ultrasound. Endocrinol Metab Clin North Am. 2001;30(2):339-60, viii-ix. 